Abstract

Within the current Australian health system is the understanding of a need to change from the predominate biomedical model to incorporate a comprehensive primary health care centred approach, embracing the social contexts of health and wellbeing. Recent research investigated the benefits of the primary health care philosophy and strategies in relation to the Rainbows program which addresses grief and loss in primary school aged students in Western Australia. A multidisciplinary collaboration between the Western Australian Departments of Health and Education enabled community school health nurse coordinators to train teacher facilitators in the implementation of Rainbows, enabling support for students and their parents. The results of this qualitative study indicate that all participants regard Rainbows as effective, with many perceived benefits to students and their families.

Key words: Comprehensive primary health care; Rainbows Program; Community health; Grief and loss 


\section{Rainbows: A Primary Health Care Initiative for Primary Schools}

\section{Introduction}

Within the current Australian health system is the emerging understanding of a need to change from the status quo of the predominate biomedical model to incorporate a comprehensive primary health care centred approach. Primary health care embraces social contexts of health and wellbeing, developing long term relationships with health care consumers to promote community participation and control over their health services. A focus on equity, access, empowerment and intersectoral partnerships intensifies the need to view health holistically, taking into account physical, psychosocial and environmental factors (McMurray, 2008). The Rainbows Program is a grief and loss recovery program for primary school aged children who have experienced loss such as death in the family, parental divorce or other painful transitions. Facilitators have embraced a primary health care approach to address a range of social and community factors impacting on the students, assisting to positively resolve and accommodate changes that have taken place in their lives. This paper will feature an evaluation of the Rainbows, highlighting the primary health care approach underpinning program delivery to primary school aged students and their families.

\section{Background}

Health is a multidimensional concept, not solely viewing physical wellbeing of individuals but the social, emotional and cultural wellbeing of people and whole communities (Eckermann et al., 2010), recognising that good health is critical for social, economic and personal development and for quality of life (The Standing Committee on Social Affairs, Science and Technology, 2009). A social model of health highlights the wide range of family, societal, economic and environmental impacts on the health of individuals or communities, acknowledging complexities of health and wellbeing that are not able to be comprehensively addressed through biomedical and bio-psychosocial approaches (Guzys \& Arnott, 2014; Parry, 2011). It is important to view social determinants of health as fundamental elements towards developing primary health care approaches. These 
determinants emphasise the importance of social, economic, cultural, community and environmental impacts on health which in turn influence access and quality of health care available for populations (Eckermann et al., 2010).

Addressing both health prevention activities and disparities necessitates holistic, intersectoral approaches with government, non-government and communities working in partnership to coordinate services. These initiatives depend on sound evidence based understanding of primary health care, recognising contributing political and economic influences in structurally changing and narrowing the essential elements of primary health care. Effective partnerships facilitating primary health care approaches are vital but all parties need to appreciate and work towards common agreed targets and implementation models. As such, it is important to understand the differences between targeted and comprehensive primary health care and how these approaches may complement or detract from effective planning. Selective primary health care is a targeted approach where specific population groups or issues are identified as needing priority attention. This has been linked to health planning targets and focused outcomes (McMurray \& Clendon, 2011; de Vos et al., 2009). Comprehensive primary health care is more closely aligned to the social model of health, addressing determinants of health through multidisciplinary partnerships in addition to community controlled social changes which impact on health. Strategies to positively affect social, political, environmental and economic impacts for individuals, families and communities through sustainable, empowering practices are integral to this approach (Keleher \& MacDougall, 2011; Wass, 2000). Syme (2004) identifies the importance of empowerment in facilitating greater control over everyday health and life challenges. However, this can be viewed as a two way process. Individuals need to take responsibility for their own change but will only benefit if reciprocal changes are supported by the wider social, educational and structural environment (Tsey et al., 2005). Increased engagement opportunities are directly related to appropriate local and broader community supports. 
How best to develop enabling strategies to assist individuals and communities to foster primary health care environments is dependent on partnership approaches and these frequently result from collaboration between community health nurses and non-health professionals such as teachers. Community based child and school health nurses engage with people in a variety of settings, with comprehensive primary health care central to their professional practice. Within their scope of practice is acknowledgement of the importance of health prevention and influences of social determinants of health. Recognition of ecological environments in which clients and communities live underpins the reality of how they work in partnership to facilitate realistic, appropriate, affordable and accessible health programs and strategies.

The Rainbows Program is a grief and loss recovery program that has been available in 204 Western Australian primary schools over an eight year period since 2002. Facilitators assist grieving students experiencing loss across a spectrum of experiences, for example, death, divorce, trauma or relocation (Krouzecky, 2013). Stresses arising from these experiences contribute to a range of issues such as low self-esteem and self-efficacy, poor emotional regulation, inappropriate peer relationships and learning impediments (Cohen, Mannarino \& Deblinger, 2006). Subsequent difficulties in coping with school environments and expectations for learning underline the benefits for support within this local setting.

Development of coping strategies and open communication of feelings have been enabling features of Rainbows. Activities, group exercises and discussion with age appropriate resources aim to assist students to appropriately convey their feelings and develop constructive coping skills, all of which enhance their feelings of self-confidence and self-respect (Farber, 2006). Impacts of adverse mental health experiences in primary school age students have potential to create child, adolescent and adult dysfunctional coping systems. Barry, Domitrovich and Lara (2005) advocate for evidence based mental health promotion practices to be adapted for cultural sensitivity and applicability to different population groups. 
Children who are positively supported experience a sense of belonging, encouraging confident selfesteem central to positive lifelong mental health adjustment and behaviours (Australian Government Department of Education, Employment and Workplace Relations for the Council of Australian Governments, 2011). This is supported by Littlefield (2008) who highlights the need for effective, early intervention programs for children with behavioural, social and emotional problems, identifying multifaceted and coordinated approaches involving the students, their parents, peers and teachers as being pivotal to successful short and long term outcomes. Kramer and Laumann (2000) draw attention to the need for simultaneous intervention for parents to assist healthy family functioning, enabling positive social contexts for the students. Rainbows incorporates Prism (KidsMatter, n.d.), an adult program designed to support single parents and step parents in a range of situations including death and divorce (Krouzecky, 2013). Together, they have potential to enhance efficacy for the whole family. The program is family-centred, recognising the impact of relational impacts on the students, along with the need to facilitate support for the family unit, enabling ongoing stability and positive relationships.

Confidentiality and safe communication spaces are key features of Rainbows. Over 12 weeks, teacher facilitators work with small groups of children to encourage open discussion about their experiences, encouraging peer acceptance and respect in a non-judgemental environment. Collaboration between the Western Australian Department of Health, Child and Adolescent Community Health (CACH) and Department of Education (DOE) enabled community school health nurse coordinators to train teacher facilitators and provide support (Krouzecky, 2013). Initially community school health nurses conducted the groups and, over time, implementation has transitioned to teachers undertaking more direct facilitation. Rainbows provides a comprehensive approach to primary health care principles of accessibility, affordability, appropriate technology, health promotion activities, intersectoral collaboration and culturally appropriate care (McMurray \& Clendon, 2011), as it recognises and addresses social determinants impacting on students and their 
families. It is universally available at no cost to all students within participating schools, and principals willing to integrate the program into their schools.

There is limited formal evaluation of Rainbows in the United States (US) and none in Australia. Kramer and Lauman (2000) noted little research success within the US. In 2004-5, Faber (2006) investigated children's communication of feelings in three US Rainbows programs with similar but not identical formats to the WA model, finding encouraging changes. No formal research has previously been undertaken in WA. As such, a decision was made to undertake a research evaluation of the WA program, exploring perceptions of Rainbows and need for improvement (Krouzecky, 2013). This paper explores the primary health care delivery within the program, identifying enabling features and impediments to implementation, along with strategies for improvement.

\section{Method of Investigation}

\section{Design}

A qualitative methodology with focus group and individual interviews within each cohort was used (Liamputtong, 2013). Carlsen \& Glenton (2011) state that focus group size is usually between four and twelve participants. Student focus groups included three to five participants to mirror the small group experience already familiar to them in Rainbows sessions. Parents were interviewed individually as they attended school to collect children or by phone. Focus group size for the community health nurses was limited by the small cohort number. The sample size included 26 participants; nine students, eight teacher facilitators, six parents and three community health nurse coordinators in three schools, until data saturation was reached (Bryman, 2012). Demographic data were collected to identify participant characteristics.

Ethics approval was given by Princess Margaret Hospital Human Research Ethics Committee (1779/EP), with permission from the Western Australian Department of Education. 


\section{Sampling and Recruitment}

Twenty Perth primary schools with children 5-12 years, who had run two or more Rainbows Programs from 2008 to 2010 were identified in the south east metropolitan area, and seven randomly selected. Of these, three school principals consented to participate. Participants were teacher facilitators, parents, students and community health nurse coordinators who had used or worked in the Rainbows program. Data were collected over a six month period in 2011 as research funding became available.

Purposeful sampling was used by each school's Rainbows coordinator to identify and contact all families who had completed a Rainbows Program group within the past two years to request participation Similarly, coordinators contacted all participating teachers from the previous two years.

This type of sampling enables insight and information rich meaningful manifestations to be gained in relation to the program with bias reduced due to the study's investigation of a distinct phenomenon of interest; however the small cohort numbers do not allow generalisation of the findings to the general population (Paton, 2002). Table 1 identifies the number of participants in each demographic category.

Potential participants were sent an information letter, consent form with a return pre-paid envelope and copies of focus group or individual interview questions. On receipt of consent, mutually agreeable times were negotiated for focus group and individual interviews. Students were able to sign an informed assent form with final consent being the responsibility of parents (Krouzecky, 2013).

There were difficulties with recruitment of children and parents. Possibly, parents may have been worried that questions would upset their children; about possibly being overwhelmed when revisiting sad or difficult memories; there may have been a sense of mistrust of people outside their 
trusted family or community, and maybe concern that disclosures might lead to family and children's services involvement. Although it was originally anticipated that each group would have five to six participants, recruitment of three participants per group from three sites was considered sufficient in the context of a formative study. However, data saturation was achieved.

\section{Data collection}

Two methods of data collection were used - focus groups and individual interviews via telephone or face-to-face. Focus groups were organised for students $(n=9)$, teacher facilitators $(n=8)$ and community health nurse coordinators $(n=3)$, using semistructured questionnaires to facilitate responses. Using the same questionnaires, parents were interviewed individually either in person $(n=2)$ or by phone $(n=4)$. Due to issues arranging common times for a parent focus group, parents were interviewed individually face-to-face or via telephone.

Seven focus groups were held. Each group, except the community health nurse coordinators' group, was held at the school to which those participants were attached. The focus group method ensured a sense of familiarity and safety intended to promote willingness to answer questions openly. Student focus groups had the facilitator, who provided their Rainbows group, present in the room. These groups were recorded and facilitated by two researchers; one interacting with participants and the other being responsible for taking field notes and recoding the sessions. They maintained continuity for coding and analysis of data, and co-authored the final report. Both staff were registered nurses with community health nursing qualifications and experience, with competencies in undertaking qualitative research projects. They had fundamental counselling skills and experience; however neither had worked in the Rainbows Program. All of these researcher attributes were reviewed and approved by the Ethics Committee (Krouzecky, 2013).

All focus groups and interviews were voluntary and participants were reassured that information would be confidential and de identified following transcription with voice recordings being erased. 
They were advised that they were able to stop the interview or withdraw completely without prejudice.

\section{Data Analysis}

Part one of data analysis used thematic analysis to identify core issues and themes from participant responses were developed into a research report for the supporting funding agency. Part two of data analysis investigated the program's primary health care approach. Findings from this paper were explored within a comprehensive primary health care evaluation framework which included principles of accessibility and affordability of services, use of technology appropriate for participants, increased use of health promotion within the program, culturally appropriate services and the use of intersectoral collaboration (McMurray \& Clendon, 2011).

\section{Results}

Demographic characteristics of the four participant cohorts are shown in Table 1.

\section{Table 1 here}

Six primary health care themes were explored: Accessibility of services, Affordability of services, Rainbows services are utilising technology appropriate for participants, Increased use of health promotion within the program, Services are culturally appropriate, and Services use intersectoral collaboration. Participant responses will be used as exemplars to support findings.

\section{Accessibility of services}

The majority of respondents expressed satisfaction with accessibility of Rainbows facilitators and having program facilitation at school. However, inconsistent room availability was identified as a significant challenge for facilitators who were mindful of the importance of a sense of place and privacy. A few children suggested holding some sessions outside.

"...I've had to swap rooms four times...oh dear...it's been a nightmare!" (Teacher Facilitator) 
Emotional accessibility was highlighted as a strength, with students having safe psychological spaces in which to express themselves freely. Respondents identified how access to the range of varying activities and strategies that Rainbows provided enabled them to cope better with their individual issues.

"It's the one place she was comfortable...it was like a security blanket for her."(Parent)

"[The facilitator] is always there for you if you need help or anything."(Student)

Parents and children also identified that the option to repeat the program was beneficial, allowing them to process grief at their own pace. The opportunity to re-enter the program when they reach different ages and stages in the grieving process has potential to allow children to work towards resolution and integration of their experience and avoid complications of long-term trauma.

"I think because she's had the progression [sic - repetition] and not just one series...she's more able to cope... with everyday things that go on."(Parent)

\section{Affordability of services}

The financial aspects of the program were integrated into school budgets with participation being free to all students. Concerns were raised by some facilitators regarding sustainability in relation to costs of ongoing program materials, affordability of resources and training.

“...we accommodate every child and their needs...(Teacher Facilitator)

"We [the school] have to cover the cost of the reliefs [for training]...and that will be a difficult thing." (Teacher Facilitator)

"Workbooks are expensive...especially if you want to put a lot of children through the program."(Teacher Facilitator) 


\section{Rainbows services are utilising technology appropriate for participants}

Teacher facilitators suggested development of a web-based module version of the curriculum. Ideas for future technological involvement included exploring use of iPads. The cited advantages were that it would be cheaper and more accessible for teachers, parents and students. It would also support the school's teacher facilitators to inform other teachers unfamiliar with the Rainbows Program, thereby improving their discussions with parents and students.

"We've got iPads... we could link it to that" (Teacher Facilitator)

Teacher facilitators and coordinators were very articulate in recommending an increase in the range of resources for program content, updating current booklets, addressing different types of grief in the content and keeping group size small to three or four children only.

"I would really like to see some changes made to the (Rainbows) booklet."(Teacher Facilitator)

Although teacher facilitators and coordinators were keen to see resources updated, the second most commonly made statement from children related to how much they liked the content of Rainbows, identifying benefits of using the books. Many remembered things they did and made and mementos received as part of celebration days.

"I like the workbooks because you can colour in and that and there was fun activities and if we didn't finish them we could do finish them at home."(Student)

\section{Increased use of health promotion within the program}

The Rainbows program employs health promotion actions including: creating supportive environments, developing personals skills and contributing to building schools' mental health prevention capacities (WHO, 2014). Adherence to cornerstones of program processes such as confidentiality, respect and non-judgemental support to express feelings endorsed a sense of health promoting emotional safety and security, greatly enhancing the group experience. Within this group 
context, children stated they felt comfortable to process feelings related to their loss. Mental health promotion assisted in normalising their experience of grief:

"...they sort of see that other people might have problems...it's not just them..."(Teacher Facilitator)

An important identified Rainbows strategy was effective interpersonal communication by facilitators, along with encouragement of students to freely express themselves. This support enhanced relationship development (a health promoting behaviour) and was named by parents and facilitators as the key outcome of Rainbows.

"... what I really love is seeing the developing of the relationship..." (Teacher Facilitator)

"[She] made some friends out of kids that she wouldn't normally have played with." (Parent)

"It helped me get along with my family."(Student)

Rainbows was perceived as complimenting the school suite of mental health prevention programs. The benefits from the experience of being in the group impressed a caring school environment which felt like it blended into the rest of school culture and instilled hope into the children.

"My school have embraced it...it's part of the culture...part of what we do..."(Teacher Facilitator)

"I think because she's had the progression [sic - repetition] and not just one series...she's more able to cope... with everyday things that go on." (Parent)

Mental health programs, such as Rainbows, empower school staff to provide support early in a child's life, rather than leaving issues unresolved. It assists staff from feeling frustrated by lack of knowledge and strategies to help students. Overall, the health promoting program aims to prevent students accessing crisis clinical mental health treatment and care services. 
"...she went to the Rainbows session and was able to speak about some of her frustrations...she just...I saw a difference in a couple of days."(Parent)

“... we're supposed to educate them in the $3 R$ 's... but if they're not ready for that then you can't do much...you have to get them to that point..."(Teacher Facilitator)

"Feeling like I'm making a difference with the children's confidence and self-esteem" (Teacher Facilitator)

"[My child's] confidence grew... and I think it was...pretty much as a result of the Rainbows Program..." (Parent)

\section{Services are culturally appropriate}

Emotional support was also seen as benefitting participants from all cultural groups within the schools, with the experience of having fun by all being described by students and teachers.

"...they love to go...never had anybody who said 'no' they don't want to go..."(Teacher Facilitator) Parent responses did not identify disagreement with appropriateness of information.

"What Rainbows taught her reinforced what I was teaching her at home."(Parent)

However, teacher facilitators and coordinators felt that Rainbows booklets and resources were either dated or culturally inappropriate to the Australian context and in need of refurbishing. Effective interpersonal communication by facilitators along with encouragement and freedom of personal expression by students encouraged relationship development, and were highlighted by parents and facilitators as key culturally appropriate outcomes. 
"The workbooks are not good... a little old-fashioned, I think... with the pictures and...old-fashioned and...there's too many pages in there...and duplicate stuff." (Teacher Facilitator)

\section{Services use intersectoral collaboration}

Intersectoral collaboration using expertise of community health nurse coordinators and teachers was viewed as a program strength. Many respondents described generalised benefits of having Rainbows in the school community where there were multiple benefits including teacher facilitators. These thoughts were understood by the researchers to reflect a sense of value held for the program.

"We can talk to the coordinator if we feel there is a need...you know a particular child..." (Teacher Facilitator)

Children are not experiencing grief in isolation from their families and communities. An identified weakness was lack of awareness by parents and facilitators regarding availability of complementary parent support programs such as Prism (KidsMatter, n.d.). Engagement of not-for-profit agencies to provide parent grief and loss prevention support programs to local clusters of schools potentially could strengthen program effects for children.

Interdisciplinary approaches are integral to successful long and short term outcomes (Littlefield, 2008), directing attention to the importance of the impact of Rainbows on students' coping strategies, grief resolution and lifelong health trajectories. Information exchange in relation to parent support between parents, teacher facilitators, Rainbows Coordinators and other stakeholders has potential not only to assist parents but also enhance a family-centred approach for students. Teacher facilitators were aware of the benefits of collaboration with community health nurse coordinators.

"It's just nice to network and just you know, share stories and just get some new ideas."(Teacher Facilitator) 
"... when something happened, I could ring and say, look, I'm worried about [child] [who] won't talk to me about it, this is what has happened...so [the facilitator] would then go an speak to her about it..." (Parent)

\section{Discussion}

This appears to be the first Australian study to explore perceptions of Rainbows and need for improvement within a primary health care context. Although specific to metropolitan WA, results identify significant positive program engagement with students, parents and teachers and important effects for students. Encouraging development of student coping skills, increased self-esteem, integration and communication of feelings about their losses were constructive findings compared to scant national and international Rainbows research data, although confirming Faber's (2006) findings of enhanced communication skills. As identified by Cohen et al. (2006), beneficial stress regulation has potential to reduce lifelong adverse health and learning issues.

Comprehensive primary health care acknowledges the impact of social determinants of health on students' and their families' lives, which is an important characteristic of Rainbows. Accessibility to the program was a not a barrier to participation, with emotional accessibility identified as a program strength. No financial costs for students and parents reduced stresses of participation. Rainbows curriculum content and interprofessional facilitation were viewed as being culturally appropriate by all participants, establishing early positive support for social and cultural wellbeing for students, families and school communities (Eckermann et al., 2010).

In this study, the Rainbows program was perceived as having a high degree of acceptance from all participants. They were able to identify strengths and areas for improvement and expressed the need for program continuance. Central to this is recognition of the importance of underpinning primary health care philosophy and strategies. Programs such as Rainbows view students and their families holistically, identifying grief and loss and subsequent emotional health as impacting on 
lifelong trajectories of social and personal development and quality of life (The Standing Committee on Social Affairs, Science and Technology, 2009; Australian Government Department of Education, Employment and Workplace Relations for the Council of Australian Governments, 2011).

The ability of Rainbows to recognise impacts of social determinants of health on students and families, facilitating positive emotional development through a comprehensive primary health care approach, has demonstrated encouraging affirmative outcomes for this population group. The drivers of positive psychological health and learning have been located in a culturally relevant, interdisciplinary approach, with facilitators and coordinators understanding how inequities with children impact on lifelong trajectories affecting health, learning, behaviour management, employment and enjoyment of life. As acknowledged by Syme (2004), helping students to undertake greater control over their life challenges encourages personal and family-centred changes such as enhanced communication skills and willingness to assume greater responsibility for educational and life pathways.

Participants suggested changes to content presentation. An issue with constant room changes within the schools was identified as impacting on the creation of safe, confidential places for students to meet. Costs of curriculum materials were of concern to teacher facilitators; although this did not affect students in the short term, there are implications for long term financial sustainability for schools to support Rainbows which could be addressed by sharing limited resources in small geographical areas. Additionally, there were a number of challenges identified with the program's content including use of contemporary curriculum material and teaching technologies. Referral of parents to preventative support has been acknowledged as an issue of concern, with potential to enhance positive family-centred social supports for students if they were able to participate in these complementary programs (Kramer \& Laumann, 2000; Krouzecky, 2013).

Overall, the majority of comments from all participants related to positive impacts and experiences of the Rainbows program. Findings have confirmed the ability of a comprehensive primary health 
care approach to positively influence social, emotional and cognitive development of the students, while being supportive for their families.

\section{Limitations}

There are limitations as to transferability of findings to the broader community or other community groups supporting children experiencing life altering changes or grief. As this is a small, formative study with no quantitative data, it is accepted that broad generalizability and transferability of findings are not able to be made. However, similarities may be identified for other areas in which Rainbows is being delivered.

\section{Conclusion}

Rainbows is emerging as an effective program, with benefits to students and their families. It is based on a comprehensive primary health care framework, recognising and acknowledging impacting social determinants.

The ability of staff to work in culturally relevant partnerships has been integral to building meaningful and sustainable program strategies. Rainbows activities have demonstrated successful elements of practice and outcomes. However, addressing identified financial and contemporary curriculum issues relating to ongoing effectiveness and sustainability are fundamental if outcomes are to be upheld.

There is a need for ongoing research studies for Rainbows both nationally and internationally, to further inform program and policy development for a range of population groups. If equitable access to this valuable grief and loss support is to be enhanced, further evidence based facilitating indicators need to be ascertained and progressed.

Recommendations are made for Rainbows management to continue making the program available for primary schools in addition to secondary schools in metropolitan, rural and remote areas. 
Investigation is recommended to ascertain the best approach for supporting parents, such as notfor-profit community agencies working in partnership with schools.

The development of comprehensive primary health care frameworks and strategies is integral to sustaining initiatives such as Rainbows. Grief and loss are complex issues. However this study has demonstrated positive outcomes indicating the program is working with school communities as empowered partners. 


\section{References}

Australian Government Department of Education, Employment and Workplace Relations for the Council of Australian Governments (2011). My time, our place. Framework for school aged care in Australia. Canberra, ACT: Commonwealth of Australia.

Barry, M., Domitrovich, C., \& Lara, A.M. (2005). The implementation of mental health promotion programmes. Promotion and Education Supplement 2, 30-36.

Bryman, A. (2012) Social research methods ( ${ }^{\text {th }}$ ed.). Oxford: Oxford University Press.

Carlsen, B., \& Glenton, C. (2011). What about N? A methodological study of sample-size reporting in focus group studies. BMC Medical Research Methodology 11(26). Retrieved from http://www.biomedcentral.com/content/pdf/1471-2288-11-26.pdf

Cohen, J., Mannarino, A., \& Deblinger, E. (2006). Treating trauma and traumatic grief in children and adolescents. New York, USA: The Guilford Press.

De Vos, P., Malaise, G., De Ceukelaire, W., Perez, D., Lefevre, P., \& Van der Stuyft, P. (2009). Participation and empowerment in primary health care: From Alma Ata to the era of globalisation. Social Medicine, 4(2), 121-127.

Eckermann, A-K, Dowd, T., Chong, E., Nixon, L., Gray, R., \& Johnson, S. (2010). Binan Goonj. Bridging cultures in Aboriginal health ( ${ }^{\text {rd }}$ ed.). Chatswood, NSW: Elsevier.

Farber, M. L. Z. (2006). Rainbows Empirical Evaluation: Data Analysis of Children's Communication of Feelings in Three Programs during 2004 and 2005. National Research Centre for Child and Family Services, Washington, DC: The Catholic University of America.

Guzys, D., \& Arnott, N. (2014). The social model of health. IN An Introduction to Community and primary Health care (Guzys, D., \& Petrie, E. (Eds.). Port Melbourne, Vic: Cambridge University Press. p. 4-5.

Keleher, H., \& MacDougall, C. (2011). Understanding health ( $3^{\text {rd }}$ ed.). South Melbourne, Vic.: Oxford.

KidsMatter (n.d.). Rainbows: Prism. Retrieved from

https://www.kidsmatter.edu.au/primary/programs/rainbows-prism

Kramer, L., \& Laumann, G. (2000). Supporting children who have experienced parental divorce: An evaluation of the Rainbows program: Final Report. Department of Human and Community Development: University of Illinois at Urbana-Champaign.

Krouzecky, M. (2013). Rainbows - supporting grief and loss in primary school children. An investigation of student, parent, teacher and coordinator perceptions of the Rainbows Program in selected District Primary Schools in the Armadale Community Health region, WA. Perth, WA: Child and Adolescent Community Health.

Liamputtong, P.(2013). Qualitative research methods (4th ed.). South Melbourne, Vic: Oxford. 
Littlefield, L. (2008). Towards a comprehensive national early intervention program for children with mental health problems. Advances in Mental Health, 7(1), 5-9.

Mahmud, A.J., Olander, E., Eriksén, S., \& Haglund, B.J.A. (2013). Health communication in primary health care -A case study of ICT development for health promotion. Medical Informatics and Decision Making, 13(17), 1-15. Retrieved from http://www.biomedcentral.com/content/pdf/1472-6947-13-17.pdf

McMurray, A, (2008). Culture specific care for Indigenous people: A primary health care perspective. Contemporary Nurse, 28(1-2), 165-172.

McMurray, A., \& Clendon, J. (2011). Community health and wellness. Primary health care in practice ( $4^{\text {th }}$ ed.). Chatswood, NSW: Elsevier.

Parry, Y.K. (2011). Understanding the relationship between the social determinants of health (DSH), Paediatric emergency department use and the provision of primary care: A mixed method analysis. Doctor of Philosophy thesis, Flinders University, Adelaide. Retrieved from http://theses.flinders.edu.au/uploads/approved/adt SFU20120321.103900/public/02whole.pd $\underline{f}$

Queensland Government, Education Queensland (2005). Professional standards for teachers. Guidelines for professional practice. Brisbane, Qld: Author. Retrieved from http://education.qld.gov.au/staff/development/pdfs/profstandards.pdf

Patton, M.Q. (2002). Qualitative research and evaluation methods ( $3^{\text {rd }}$ ed.). Thousand Oaks, CA:Sage.

Strubert-Speziale, H.S., \& Carpenter, D.R. (2003). Qualitative research in nursing: Advancing the humanistic imperative. Philadelphia, USA: Lippincott Williams and Wilkins.

Syme, S.L. (2004). Social determinants of health: the community as an empowered partner. Prev Chronic Dis [serial online] Retrieved from http://www.cdc.gov/pcd/issues/2004/jan/03 0001.htm

The Standing Senate Committee on Social Affairs, Science and Technology (2009). A healthy, productive Canada: A determinant of health approach, Final Report of Senate Subcommittee on Population Health. Ottawa, Canada: Author. Retrieved from http://senate-Senat.ca/healthe.asp

Tsey, K., Gibson, T., Whiteside, M., Cadet-James, Y., Haswell-Elkins, M., McCalman, J., \& Wilson, A. (2005). The role of empowerment through life skills development in building comprehensive primary health care systems in Indigenous Australia. Journal of Primary Health, 11(2), 16-25.

World Health Organisation (2014). The Ottawa Charter for Health Promotion. Retrieved from http://www.who.int/healthpromotion/conferences/previous/ottawa/en/ 
Table 1 Participant Demographics

\begin{tabular}{|c|c|c|c|c|c|c|}
\hline \multirow[t]{2}{*}{$\begin{array}{l}\text { Participant } \\
\text { type }\end{array}$} & \multirow[t]{2}{*}{$\begin{array}{l}\text { Number of } \\
\text { groups } \\
\text { (Total) }\end{array}$} & \multicolumn{2}{|c|}{$\begin{array}{l}\text { Number of } \\
\text { participants }\end{array}$} & \multirow[t]{2}{*}{$\begin{array}{l}\text { Years of } \\
\text { professional } \\
\text { experience } \\
\text { (Range) }\end{array}$} & \multirow[t]{2}{*}{$\begin{array}{l}\text { Years of } \\
\text { Rainbows } \\
\text { experience } \\
\text { (Range) }\end{array}$} & \multirow[t]{2}{*}{$\begin{array}{l}\text { Age in } \\
\text { years } \\
\text { (Range) }\end{array}$} \\
\hline & & Male & Female & & & \\
\hline Coordinators & 1 & 0 & 3 & $n / a$ & $n / a$ & $\begin{array}{l}\text { Not } \\
\text { collected }\end{array}$ \\
\hline $\begin{array}{l}\text { Teacher } \\
\text { facilitators }\end{array}$ & 3 & 0 & 8 & 3-35 & $2-7$ & $\begin{array}{l}\text { Not } \\
\text { collected }\end{array}$ \\
\hline Children & 3 & 1 & 8 & $n / a$ & $n / a$ & 7-11yrs \\
\hline Parents & $\mathrm{n} / \mathrm{a} *$ & 0 & 6 & $n / a$ & $n / a$ & $\begin{array}{l}\text { Not } \\
\text { collected }\end{array}$ \\
\hline TOTAL & 7 & 1 & 25 & & & \\
\hline
\end{tabular}

(Adapted, Krouzecky, 2013) 